\title{
«Historias rotas»: la memoria y el olvido en la construcción de la identidad migrante en el teatro español actual*
}

\author{
«Broken Histories»: Memory and Forgetting \\ in the Construction of Migrant Identity \\ in the Contemporary Spanish Theatre
}

\author{
Ivana Krpan \\ Universidad de Zagreb \\ ivanakrpan@yahoo.es \\ ORCID iD: https://orcid.org/0000-0001-8752-711X
}

\begin{abstract}
RESUMEN
El artículo analiza las estrategias discursivas de la memoria migrante en la dramaturgia española en la entrada del siglo XXI. Se reconstruyen las «memorias rotas» de la inmigración extranjera en España y se analiza el proceso simultáneo de consolidación y deconstrucción del modelo histórico nacional en el trabajo dialéctico entre la memoria y el olvido de los personajes dramáticos. Las obras estudiadas de Jerónimo López Mozo, Carles Batlle, Ignacio del Moral, Juan Diego Botto, Alberto de Casso Basterrechea y Malco Arija Martínez tematizan la experiencia traumática provocada por el desplazamiento del migrante y la ruptura de la linealidad histórica de su origen, cuestionando la memoria colectiva como proyecto de homogeneidad nacional. La estructura dramática facilita la deconstrucción de los elementos que mantienen la solidez de las grandes narraciones históricas y las subvierte en la reconstrucción teatral de la «postmemoria».
\end{abstract}

Palabras Clave: teatro español actual; migración; memoria.

\section{ABSTRACT}

The article analyzes the discursive strategies of the migrant memory in the Spanish dramaturgy in the early years of the $21^{\text {st }}$ century. The study reconstructs the «broken memories» of foreign immigration in Spain as a result of the simultaneous consolidative and deconstructive processes of the national historical modeling within a dialectical work between memory and

* Este trabajo se realizó durante la estancia postdoctoral en Salamanca que fue objeto del contrato financiado por la Cátedra de Altos Estudios del Español de la Universidad de Salamanca en 2015. 
forgetting. Jerónimo López Mozo, Carles Batlle, Ignacio del Moral, Juan Diego Botto, Alberto de Casso Basterrechea and Malco Arija Martínez's dramas relate the traumatic experience caused by the displacement of the migrant and the break of the historical linearity of its origin, by questioning the collective memory as a project of national homogeneity. The dramatic structure facilitates the deconstruction of the elements that maintain the historical narratives and subvert them in the theatrical reconstruction of the «postmemory».

Key words: Contemporary Spanish Theatre; Migration; Memory.

\section{INTRODUCCIÓN}

Las migraciones han marcado toda la historia de la Humanidad como procesos naturales de supervivencia y adaptación. Sin embargo, a partir de la consolidación de los estados-naciones, el desplazamiento y el abandono del país de origen suscitaron una serie de términos de índole político-social como la diáspora, la (in/e)migración, el exilio, la otredad, la transculturalidad, etc. El estudio de estos conceptos dentro del paradigma nacional y la metanarratividad histórica empezó a ser uno de los temas recurrentes de la semiótica cultural desde la segunda mitad del siglo XX hasta nuestros días. En cuanto a la cultura española, la revaloración del pasado y de los esquemas representativos de la Historia se aceleró a partir de los años 90, debido a ciertos acontecimientos socio-culturales ${ }^{1}$ y al auge de inmigración que iba aumentando a la entrada del siglo XXI. Dado que «la identidad se forja principalmente en torno a esa alteridad que representa el Otro procedente de la inmigración, fenómeno este que se ha convertido en el gran desafío político, social y cultural» (Iglesias Santos 2010: 10), estos cambios requirieron que la sociedad española volviera a imaginarse en un contexto heterocomunitario y que cuestionara su pasado para poder crear nuevos modos de interacción social de una ciudadanía multicultural.

El teatro fue también uno de los motores en la dinamización de la sociedad, como expresión artística que promovía el diálogo, la comunicación no verbal, el lenguaje corporal y la inmediatez del acto socio-cultural de la puesta en escena. La dramaturgia española nos proporciona numerosas obras que enfocan esa cuestión a través de la temática (in)migrante y desde una mirada crítica y comprometida, enfrentando la manipulación interesada de la historia a una alianza entre el teatro, la historia y la memoria (Monleón y Diago 2007) de las

\footnotetext{
1 Nos referimos a una serie de eventos celebrados en 1992 que fomentaron la idea de la sociedad española como núcleo de la fusión transcultural; en el mismo año se organizó la Exposición Universal en Sevilla, se celebraron los Juegos Olímpicos en Barcelona, Madrid fue nominada la Capital Europea de la Cultura y se conmemoró el V Centenario del Descubrimiento de América.
} 
distintas voces que pertenecen a la comunidad multicultural contemporánea. Las migraciones masivas de las últimas décadas (hiperbolizada por los medios de comunicación) y la semiótica de la memoria histórica crearon la necesidad de hablar sobre el Otro, como un síntoma claro de la crisis cultural europea y la obligación de analizar, relativizar y reescribir su propio pasado (Eagleton 2002: 37). Los dramas que se estudiarán a continuación muestran la tendencia de reescribir los conceptos históricos y la memoria colectiva a través de la experiencia (in)migrante y de la cuestión del Otro en la sociedad española. No obstante, la actualidad del tema no proporcionó la mediación escénica que llegara a alcanzar el mismo nivel en cuanto a la integración del (in)migrante en la escena contemporánea que podría haberle otorgado más visibilidad en el espacio público. A pesar del reconocimiento literario visible en el número de textos editados y premiados, las representaciones no se abrieron a una polifonía escénica que pudiera asumir las voces de sus protagonistas. Pero vayamos por partes.

\section{RoOTS Y ROUTES: EL MARCO TEÓRICO DE LA MIGRACIÓN}

Los planteamientos teóricos en el campo de la filosofía histórica y de la semiótica cultural de la segunda mitad del siglo XX marcaron los cambios en la dramaturgia española contemporánea. Los textos dramáticos de la última década del siglo pasado y del principio del siglo XXI pueden vincularse a los preceptos ideológico-poéticos acerca de la ficcionalización de la historia formulados por Lukács (1962), White (1987), Anderson (1990), Ricœur (1999) y Hobsbawm (2002). El estatus (in)migrante cuestiona el concepto de nación como «la comunidad imaginada» (Anderson 1990) cuyos discursos instrumentalizan el pasado y fortalecen la memoria colectiva a base de una linealidad histórica inventada. A estas premisas socio-políticas se suman otras de índole histórico-narrativa, demostrando que

... a pesar de las diferencias evidentes que existen entre el relato histórico y el de ficción, ambos poseen una estructura narrativa común, que nos permite considerar el ámbito de la narración como un modelo discursivo homogéneo [...], ambos contribuyen a describir o a redescribir nuestra condición histórica y a nosotros como seres históricos (Ricœur 1999: 83-84).

La consolidación de una memoria estable se debe al poder narrativo del relato histórico que estructura los acontecimientos dispersos y azarosos del pasado en una línea causal y explicativa que facilita presentar la historia como una sucesión lógica del tiempo. En este sentido, el discurso histórico aspira a «la coherencia, la integridad, la totalidad, y la imagen encerrada de la vida, una 
imagen que es y solamente puede ser imaginaria» $)^{2}$ (White 1987: 24). Por estas razones el material histórico a menudo colisiona con las experiencias individuales y se distorsiona en las prácticas inherentes a la memorización y el olvido personales en un trabajo simultáneo de recuerdo y vigilancia, ambos «solidarios y necesarios para la ocupación completa del tiempo» (Augé 1998: 103).

Dentro de estos márgenes teóricos, la particularidad de la memoria (e/in) migrante consiste en la doble articulación de las raíces y los raíles ${ }^{3}$ (Clifford 1997: 251); entre los mitos acerca del origen, conservados, modificados y adaptados a la memoria de los descendientes, y por otro lado, la rotura del desarrollo histórico lineal y progresivo, debido al desplazamiento del migrante. Esta dialéctica origina una historia rota como experiencia traumática en la configuración lineal del tiempo, donde «el presente está siempre oscurecido por el pasado que, a su vez, es deseado, pero también obstruido» ${ }^{4}$ (Clifford 1997: 264).

A continuación se analizará la dramatización de estos conceptos en las obras que problematizan la condición del (in)migrante en la sociedad española y tienden a reconstruir el discurso de las tradiciones inventadas como un «conjunto de prácticas, regidas por las normas abierta o tácitamente aceptadas, y los rituales de índole simbólica, que tratan de inculcar ciertos valores y normas de comportamiento a base de la repetición que automáticamente implica la continuidad del pasado» ${ }^{5}$ (Hobsbawm 2002: 1). Estudiaremos algunos ejemplos dramáticos que reconstruyen los modelos culturales estandarizados por la semiótica de la memoria y las modificaciones del legado nacional causadas por los procesos dinámicos y cambiantes de las migraciones postnacionales.

Como hemos advertido en la introducción, la dramaturgia española desde la última década del siglo XX hasta nuestros días ha ido desmontando las construcciones históricas impuestas por la instrumentalización del pasado. Independientemente del enredo dramático, sus planteamientos ideológicos giran en torno a conceptos filosófico-históricos recurrentes: la inestabilidad del concepto nacional en la era global, la historia nacional y los discursos metanarrativos, la ruptura del pasado lineal del migrante, y la fetichización de la imagen del extranjero dentro del paradigma nacional de la sociedad de acogida. En cuanto a la estructura interna, los autores apuestan por un ajuste sincrónico entre el pasado de la historia dramatizada, el presente de la escritura y la ac-

2 Todas las traducciones de inglés al español son el trabajo de la autora del artículo. El original en inglés aparecerá en la notas a pie de la página. En esta cita: «coherence, integrity, fullness, and closure of an image of life that is and can only be imaginary».

3 «roots and routes».

${ }^{4}$ «the present constantly shadowed by a past that is also a desired, but obstructed».

5 «a set of practices, normally governed by overtly or tacitly accepted rules and of a ritual or symbolic nature, which seek to inculcate certain values and norms of behavior by repetition, which automatically implies continuity with the past». 
tualidad de la puesta en escena. Los montajes escénicos facilitan la configuración del tiempo que resalta el poder de las memorias personales en la reconstrucción del pasado. A este marco temático y formal pertenece la obra de una veintena de autores españoles entre los años 90 y la primera década del siglo XXI, reconocidos en las escenas española e internacional, a los que se suma un número considerable de autores jóvenes que trataron esos asuntos en algunas de sus obras primerizas. En este trabajo estudiaremos las obras dramáticas que enfocan el tema (in)migrante principalmente dentro del concepto de historia rota y cuyo eje temático gira en torno a la dualidad establecida entre las raíces y los raíles que denominan la historia íntima del protagonista. Dentro de este planteamiento dramático se inscriben las obras: La mirada del hombre oscuro (1992), de Ignacio del Moral, premiada por la SGAE en 1991; Alhán (1997), ganadora del Premio Tirso de Molina en 1996, de Jerónimo López Mozo; Los viernes del Hotel Luna Caribe (2000), ganadora del Premio Calderón de la Barca en 1999, de Alberto de Casso Basterrechea; Patera (2004), galardonada con el Premio Born en 2003, de Juan Pablo Vallejo; Tentación (2005), de Carles Batlle; y cuatro monólogos de Juan Diego Botto y Roberto Cossa publicados bajo el título El privilegio de ser perro $(2005)^{6}$. Asimismo, a estos textos sumamos la obra Akua, perdida en el tiempo (2003), de Malco Arija Martínez que, entre el grupo de dramaturgos jóvenes de la RESAD, muestra interés por el tema (in)migrante e igualmente desarrolla la idea principal dentro de la estructura dramática de historia rota ${ }^{7}$.

${ }^{6}$ Este estudio trata exclusivamente las obras en cuyo subtexto yace el concepto de historia rota. Por lo tanto, el análisis excluye las obras que dramatizan el tema (in)migrante desde otros enfoques o donde el concepto de historia rota no se desarrolla de una manera clara y coherente. Aunque en la época estudiada (la última década del siglo XX y la primera del siglo XXI) aparecen numerosas obras dramáticas sobre la cuestión (in)migrante, muchas de ellas están orientadas hacia la sociedad de acogida, haciendo hincapié en otros aspectos de la convivencia social y de la condición del extranjero, como la violencia por parte de la cultura receptora, el rechazo del Otro y el abuso del estatus precario del inmigrante. Entre las más conocidas destacan: Veinte años no es nada (1994), de Eduardo Recabarren; Los malditos (1995), de Raúl Hernández Garrido; Salvajes (1996), de José Luis Alonso de Santos; Cachorros de negro mirar (1999), de Paloma Pedrero; Lista negra (1999), de Yolanda Pallín; Combate (2000), de Carles Batlle; Animales nocturnos (2003), de Juan Mayorga; Forasteros (2006), de Sergi Belbel, De Jerusalén a Jericó (2006), de Ignacio Amestoy; y Maldita cocina (2007), de Fermín Cabal.

${ }^{7}$ Igualmente, el presente trabajo no incluye los textos de dramaturgos jóvenes que en el principio del siglo XXI tratan la cuestión (in)migrante desde otros enfoques: ;Comed mucha fruta! (1999), de Mahor Galilea Pascual; Emigrantes (1999), de Sara Rosenberg; Phil o Sophía (2002), de Jesús Laiz; Taihú, cabaret oriental (2003), de José Cruz; Amarga ilusión (2003), de Francisco José Martínez Cernadas, y Ulises (2003), de Alfonso Pindado. 


\section{LA MEMORIA DE LA MIGRACIÓN EN LA DRAMATURGIA ESPAÑOLA}

En los textos estudiados las vertientes temáticas giran en torno a la (in) migración extranjera en España y a las relaciones que se establecen entre el forastero y la sociedad de acogida. No obstante, el enredo suele ser solamente una base para crear el conflicto dramático acerca de la identidad histórica, el tema del Otro, la memoria y las proyecciones sobre el futuro de una sociedad cada vez más diferenciada, en el sentido cultural, racial, étnico, económico y social, tomando en cuenta la precariedad del migrante. El abandono del hogar provoca varias actitudes hacia el pasado del protagonista; el cambio puede simultáneamente consolidar (afirmar) la construcción homogénea de la historia nacional o perjudicar (negar) su estabilidad. En los textos dramáticos se establece un vínculo dialéctico entre los desplazamientos (routes) y los orígenes (roots), donde el primer concepto niega o cuestiona el segundo, en una negociación constante entre la memoria y el olvido. La migración del individuo incluye los dos aspectos que se activan en la relectura de la condición histórico-nacional de los protagonistas y en la deconstrucción de los esquemas culturales que reafirman el mito del origen en su (post)memoria.

Empezaremos a ilustrar estas ideas con la obra de Alberto de Casso Basterrechea (2000), Los viernes del Hotel Luna Caribe, donde el autor problematiza la relación cómplice-antagónica entre los factores constitutivos de la memoria (in)migrante a través de la experiencia de tres mujeres cubanas en Europa. El drama es protagonizado por la madre y sus dos hijas que vienen a España con la promesa de trabajo como camareras en un hotel que resulta ser un prostíbulo en una carretera nacional en los alrededores de Madrid. Dado que las mujeres anhelan empezar una vida nueva en un país más próspero que el suyo y conseguir el bienestar soñado, están dispuestas a sufrir el maltrato físico y laboral de la sociedad de acogida y, a consecuencia del desplazamiento, aceptan cortar el hilo que les une a su «comunidad imaginada» y su historia cubana. Sin embargo, los recuerdos de su patria abandonada les persiguen en la vida nueva, obstruyen el escape de las raíces y continuamente invocan su estatus (in)migrante que no les permite vivir el olvido deseado.

Varios motivos reiteran las imágenes de su pasado; en primer lugar, el nombre del hotel-prostíbulo, Luna Caribe, recuerda de una manera exótico-grotesca el espacio geográfico de su origen y enfatiza la imposibilidad de cruzar las coordenadas socio-culturales en que las mujeres están enclaustradas. Otra imagen que evoca el pasado es el atropello de una prostituta en la carretera cercana al Hotel, que relaciona las condiciones de su muerte y su destino trágico con el fallecimiento de una chica joven en las calles cubanas, justamente uno de los últimos recuerdos que las protagonistas se llevaron de su país. Asimismo, el maltrato, la pobreza, la ignorancia y la injusticia de la cotidianeidad cubana se reiteran y multiplican en la memoria de las protagonistas al enfrentar las mismas condiciones de vida en España. La migración y el despla- 
zamiento del recuerdo a otro ámbito referencial reproducen los nuevos significados dentro de una dimensión transnacional (Bhabha 2006: 247), pero la categoría (in)migrante perpetúa la simbología opresiva del pasado violento sobre los personajes femeninos. De esta forma encontramos «por un lado, la identificación del sujeto con el lugar que ocupa, y al que se halla en cierto modo condenado, y por otro, un desplazamiento de las connotaciones semánticas involucradas en el espacio representado, que 'destiñen' o se proyectan sobre las peripecias de unos personajes en movimiento» (Conte Imbert 2010: 37). Finalmente, la desvinculación de la «comunidad imaginada» y del seno familiar se invoca con el recuerdo de la abuela que se quedó en Cuba; en los momentos previos a la emigración de las protagonistas su antecesora rompe un espejo y así anuncia la futura rotura de la historia familiar y personal de sus descendientes. El vínculo entre los personajes resalta el tema en cuestión, ya que el trabajo de la memoria tiende a reactivar y re-encarnar las estructuras social/nacionales alejadas mediante las formas individuales y familiares más potentes de la expresión estética (Hirsch 2008: 111). En este caso, el espejo roto es el síntoma claro de la pérdida del modelo familiar que se asocia con el trauma del abandono de la tierra natal y la ruptura de la historia lineal de las protagonistas.

La obra Tentación, de Carles Batlle, estrenada en 2004, es otro ejemplo de la reconstrucción del esquema cultural/nacional a través del legado familiar, en un contexto conservador que imposibilita el desarraigo de los personajes de las mitificaciones históricas en las que están insertados. El drama es protagonizado por dos jóvenes que se enamoran y desean empezar la vida en pareja; el español Guillem de ideología tradicionalista y la marroquí Aixa, literalmente perseguida por la historia en el personaje de su padre Hassan que viene a España a buscarla. La falta de comprensión entre ellos se enfatiza con la técnica monologuista y cinematográfica, que a la vez sirve para crear un espacio aislado donde se dejan escuchar las voces íntimas de los personajes. Para cada uno de ellos el extranjero supone una amenaza a su herencia monocultural y la descomposición de la imagen socio-cultural estable. Por un lado, el joven español siente la necesidad de consolidar la memoria, intimidado por la fusión cultural que supone su relación sentimental con Aixa, y afirmando que «había estado a punto de caer en una trampa terrible, había estado a punto de traicionar la memoria de "los míos", de lanzar mis muebles, había estado a punto de vender mi pureza a la tentación de una carne esplendorosamente extraña» (Batlle 2005: 62). Por otro lado, Aixa emplea la estrategia de olvido para construir y conservar un porvenir imaginado con Guillem, vengándose del autoritarismo de su padre y de la memoria que le impedía decidir por sí misma (Foguet i Boreu 2005: 18). Finalmente, el personaje de Hassan, el padre de Aixa, añora su tierra natal y es el signo de la memoria familiar marroquí que invade el terreno europeo difícilmente conquistado por el olvido de Aixa. Dentro de este triángulo el autor sitúa la idea de la memoria fetiche que perdura solamente 
como un objeto museológico y que, al no ser de utilidad práctica en el mundo global-capitalista, sirve de decoración anticuada a una tradición perdida que no llega a perpetuarse en la postmemoria: «GUILLEM (a Hassan): Memoria. ¿De qué nos sirve la memoria? Tú eres el único moro mierdoso que conocía que no se parapetaba en la memoria para sobrevivir. Y hacías bien, no haría falta ni una generación para que vuestra memoria fuese desterrada, olvidada, menospreciada por vuestros hijos» (Batlle 2005: 61-62).

La emigración de Aixa provoca la ruptura del pasado familiar; el viaje marítimo introduce la primera grieta en su historia rota y le trae las primeras experiencias de inseguridad por el abandono de sus raíces y la violación del pasado. Como señala Pérez-Rasilla (2010: 99):

El relato sobre la (in)migración se apoya en la imagen de un grupo de africanos que llegan desorientados a las costas meridionales a bordo de una embarcación frágil - patera, cayuco, balsa o similar - , por supuesto, de manera clandestina, y conducidos/explotados/extorsionados por tramas mafiosas. Los medios de comunicación renuevan casi a diario el relato, que ha calado en la sociedad española y que, consecuentemente, incide en la representación artística del fenómeno. [...] la fuerza plástica y emocional de esta imagen, su capacidad de condensación y de sugerencia, y su innegable condición épica contribuyen a operar poderosamente en la mentalidad colectiva.

El viaje en patera donde la joven protagonista pierde los objetos personales simboliza la primera desvinculación de su familia, de la identidad colectiva y de una tradición cuidadosamente vigilada:

\begin{abstract}
AIXA: El hombre de la barca también se cabreó porque reía. Me dio una bofetada, me dejó marcados los dedos, quería saber si lo sabían mis padres, cuántos años tenía, qué papeles llevaba, me registró la bolsa, había cosas que hacían bulto, decía, que pesaban, tenía una cámara fotográfica, [...] y también el Corán que me había regalado mi padre, y si no llego a estar atenta, el mal nacido me tira las cartas, y la libreta, y las direcciones, todo... (Batlle 2005: 31).
\end{abstract}

Lo que queda de la historia de Aixa ya no es suyo, desde el momento del embarque su pasado y su futuro van a ser manipulados y reinventados por intereses ajenos. Su «comunidad imaginada» está personificada en su padre Hassan que la persigue como una sombra del pasado, pero en el país de acogida también pierde el vínculo con su tierra y se convierte en un «moro» sin papeles cuyo recuerdo acabará enterrado «en una piscina llena de formol, y después en una fosa común, con otros brazos y piernas de gente que no tiene familia» (Batlle 2005: 56). Incluso los recuerdos del padre, el guardián de la cultura marroquí, están invadidos por la visión europeizada, propagandística e inherente a la cultura popular de los medios de comunicación. 
HASSAN: La gente de aquí se piensa que todo aquellos existe, que vivimos como en las películas, ¿cómo se puede ser tan estúpido? [...]. Imagínate que tienes quince años y que te dicen "ponte estos trapos, chaval, coge esta escopeta y vete hacia el camello, cuando demos la señal, venís todos juntos hacia aquí, ¿lo has entendido?, venís corriendo y gritando, ¿de acuerdo?” ¡Cómo nos reíamos! ¡Pero si no sabíamos montar en camello! (Batlle 2005: 27).

La memoria no nace de una experiencia verdadera, sino pertenece al campo de la imaginación del sujeto y de los demás destinatarios dentro del mismo sistema comunicativo, en un «proceso de formalización y ritualización caracterizado por las referencias al pasado, y si fuera solamente por la repetición ${ }^{8}$ (Hobsbawm 2002: 4) de los signos reconocidos dentro del código que comparten.

Dentro de este marco dramatúrgico, cabe señalar el drama de Malco Arija Martínez, Akua, perdida en el tiempo, publicado en la colección de dramaturgos jóvenes de la RESAD, Teatro. Promoción. 1998-2002 (2003). La trama sigue el destino trágico de Akua y Nubenke, dos hermanos que deciden atravesar el mar que separa la costa africana de la europea para conseguir el dinero y las medicinas para su padre enfermo. Se reitera el motivo del viaje marítimo, pero en este caso la imagen de transporte de africanos inconfundiblemente recuerda la venta de esclavos en la postmemoria de los personajes oprimidos por el neocolonialismo capitalista del mundo actual: «CABO: Los intentamos, Comandante, les golpeamos, pero no van más rápido. Algunos se caen y tenemos que parar, Comandante, se caen y no quieren levantarse aunque les golpeamos, unos llevan a otros y no se puede ir más rápido.» (Arija Martínez 2003: 49).

En pocos textos de dramaturgos jóvenes al principio del siglo XXI el concepto de historia rota se muestra tan unido al destino de los protagonistas como en este drama. La idea de la pérdida, indicada en el título, va originando una serie de motivos vinculados a dicho concepto: ruptura de la linealidad histórico-cultural, desarraigo, olvido y manipulación interesada del pasado, elementos que llegan a materializarse en el cuerpo de la protagonista. Paso a paso Akua va perdiendo las señas de identidad que la definen; primero, al desobedecer al padre que no apoya su ida, la protagonista rompe el lazo más íntimo con su pueblo que vive unido y atado a sus ritos y costumbres antiguas en una imagen perfecta de la «comunidad imaginada». La primera separación y el viaje por las tierras desconocidas del continente africano ya indican un porvenir incierto de Akua, un futuro de violencia y de traumas provocados por la ruptura con los vínculos familiares y materializados en el dolor físico de la joven. Al llegar a España la grieta de su historia rota se hace más profunda cuando se ve sumergida en el mundo de la prostitución. Esta idea se hace aún más potente

8 «a process of formalization and ritualization, characterized by reference to the past, if only by imposing repetition». 
cuando Akua se ve obligada a cambiar su aspecto físico con vestuario provocativo, maquillaje, depilación y cambio de nombre a Sheila. La separación geográfica, la mutilación corporal y la pérdida del fundamento de la identidad que es el nombre, simbolizan la ruptura de la linealidad en su relato familiar y nacional que amenaza la perduración de la tradición en la postmemoria.

AKUA: El hijo tiene que estar con el Padre. Si no, se rompe la cadena de tiempo y nadie recuerda al Padre y entonces el Padre no es inmortal y los antepasados se alejan (Arija Martínez 2003: 41).

NIGUE: A lo mejor en este árbol también se reúnen antepasados.

AKUA: No creo.

NIGUE: ¿Por qué?

AKUA: Porque nunca nadie viene a verlos. Y si nadie puede acordarse de ellos, ya están perdidos en el tiempo (Arija Martínez 2003: 73).

Además, en este ejemplo dramático, el pasado, la memoria, el futuro y la postmemoria no siguen una línea cronológica, sino que forman un tejido atemporal de elementos anacrónicos y entrelazados en la construcción completa del tiempo y de la historia de la "comunidad imaginada» cuya coherencia solo puede romper el olvido: "VOLUNTARIO: Así te acuerdas de ellos. / AKUA: Yo no me acuerdo. Están conmigo» (Arija Martínez 2003: 39). La memoria es el sinónimo de la vida misma donde la palabra y la imagen, el hecho y el recuerdo funcionan como un elemento único que mantiene los ritos familiares en la atemporalidad de la historia personal. El cuerpo traumatizado por la historia rota intenta mantener el lazo con las raíces haciendo un llamamiento a la voz interna de la consciencia y los recuerdos como puntos de encuentro con la tradición, donde la memoria tiene un papel constructivo como «un elemento crucial que mantiene la sensación de la integridad ${ }^{9}$ (Clifford 1997: 44). Sin embargo, el desplazamiento espacial y la transformación física de Akua llevan a la destrucción de la linealidad histórica, causando la pérdida de la protagonista en el tiempo y en la memoria familiar.

El mismo paradigma se encuentra en la obra Alhán, de Jerónimo López Mozo (1997), que trata la cuestión de la diáspora magrebí en España. La obra ofrece una pluralidad de perspectivas geográfico-históricas representadas en una fusión del lenguaje escénico y las proyecciones digitales de la memoria archivada en documentos históricos, periodísticos, científicos, cinematográficos y otros propios de la postmemoria cultural, que se insertan intertextual y metateatralmente en el presente dramático. La experiencia desafortunada del (in) migrante Larbi se relaciona repetitivamente con los discursos discriminatorios sobre la inmigración marroquí en varios ámbitos públicos y privados de la cultura receptora; las costumbres y la manera de vivir, el ideal de la utopía

\footnotetext{
9 «a crucial element in the maintenance of a sense of integrity».
} 
crítica y la creación estética occidental (Eagleton 2002: 29). López Mozo plantea la pregunta sobre el trauma de la (e/in)migración extranjera, pero a la vez cuestiona el patrimonio cultural español cuyos logros estéticos enmascaran las verdaderas preocupaciones éticas en la esfera social. La cuestión (in)migrante se sitúa en el nivel económico reflejado en la imposibilidad de cruzar la frontera y ejercer la ruptura deseada con el mundo considerado «tercermundista». Debido a la condición precaria del protagonista, tanto Europa como su país de origen pueden representar «la tierra rica» o «el rincón del vómito» (López Mozo 1997: 37), donde solamente el cambio del estatus económico y social representa el verdadero desplazamiento del personaje.

La condición migratoria de Larbi se relaciona con los conceptos teóricos provenientes de los estudios culturales y antropológicos a partir de la segunda mitad del siglo XX:

El sedentarismo no es una de las características genéticas de nuestra especie; se ha ido consolidando relativamente tarde, con toda probabilidad en estrecha relación con la invención de la agricultura [...]. En cualquier época, y por las razones más diversas, una parte importante de la humanidad siempre ha estado en movimiento: de forma pacífica o forzada, en simple migración o huyendo (Enzensberger 2002: 10-12).

¿Cómo definir y defender la patria? No tanto en la cuestión “¿De dónde eres?”, sino en la “¿Entre dónde eres?”10 (Clifford 1997: 36-37).

La exposición dramática aplica estas premisas a la experiencia íntima de los personajes:

LARBI: A Hans le conocí en el muelle de la Fusta. Nos sentábamos en el mismo banco. Es un holandés que pasa de los setenta y que habla todas las lenguas del mundo. Me gustaba escucharle. "Sabes, Larbi, que los hombres siempre se han movido de un sitio para otro [...]. Somos animales viajeros, nómadas. Se diga lo que se diga, uno no es de dónde nace, sino de dónde está en cada momento [...]. Algunos acabamos por no ser de ninguna parte. Vamos de ilegales por la vida. El mundo rodaría mejor si todos fuéramos apátridas" (López Mozo 1997: 201).

Las nuevas condiciones influyen en la reconstrucción de la memoria colectiva que se ajusta a las necesidades de la migración global constante. Sin embargo, si a estos procesos no precede un soporte legislativo que le permita al (in)migrante consolidar su estatus de ciudadano del mundo en el país extranjero y que no le impida mantener el lazo con su legado cultural, el desplazamiento siempre resultará traumático:

10 «What does it take to define and defend a homeland? Not so much "Where are you from?" as "Where are you between?"». 
ANCIANO: La enfermedad del exilio y la soledad se ha instalado en tu cuerpo. Padeces el mal de la tierra. Finges ignorarlo. Si no la expulsas, ésta casa será tu celda y quién sabe si no tu tumba [...]. Pon en su maleta todas sus pertenencias y haz su camino, el que estabas a punto de emprender [...].

LARBI: El regresar al pasado.

ANCIANO: A tu sitio. Es un viaje necesario. [...].

LARBI: ¡Eres una pesadilla! ¡Otro fantasma metido en mi vida! (López Mozo 1997: 129-131).

En estas circunstancias el comportamiento del protagonista se vuelve radical; Larbi, que sufre abusos por parte de las autoridades españolas y de la sociedad en general, en un giro irónico violento somete al mismo maltrato a otro inmigrante, justificando su comportamiento por el deseo de asimilar mejor las costumbres de la sociedad de acogida. Su condición (in)migrante le «hace consciente de su desarraigo, de su condición de maldito, de la imposibilidad, en suma, de salir del infierno que creyó abandonar» (Pérez-Rasilla 2010: 113).

El marco teatral facilita los ajustes del tiempo que invocan el pasado en la inmediatez presencial del cuerpo del actor y de los cambios súbitos de los signos escénicos como la luz, el sonido, el movimiento y los objetos que pueden interpolar la memoria en la experiencia vivida del presente. Estos recursos forman parte estética y constructiva de la obra Patera, de Juan Pablo Vallejo, y de la colaboración de Juan Diego Botto y Roberto Cossa en cuatro monólogos publicados bajo el título El privilegio de ser perro. El caso de Vallejo y Botto llama aún más atención, dado que ambos han vivido la experiencia de diáspora, aunque en unas condiciones bastante distintas ${ }^{11}$. La obra Patera es todo un homenaje poético-dramático a la dialéctica establecida entre la memoria colectiva, la historia familiar y el olvido. La obra se estructura en una serie de once escenas que unen el pasado, el presente y la evocación del futuro de tres (in)migrantes procedentes de América Latina y África.

Similar al destino de las protagonistas en los dramas Tentación y Akua, perdida en el tiempo, la trama encierra la metáfora del exilio en el motivo del viaje marítimo (imagen potenciada por las noticias diarias y la fetichización de las pateras en el espacio público) que borra las huellas de los pasajeros, dejando escuchar solamente los ecos de la familia al otro lado de la orilla como refugio de la memoria en extinción. En la propuesta de Vallejo la patria abandonada o el núcleo de su «comunidad imaginada», personificada en el personaje de la madre, la novia o la esposa que esperan a los protagonistas, sufre y guarda el recuerdo sobre los que se han ido:

${ }^{11}$ Botto vino a España de niño a principios de los años 80 a causa del exilio político tras la desaparición y el fallecimiento de su padre durante la dictadura de Videla, mientras Vallejo vino en la edad madura, casándose con una mujer de nacionalidad española. 
MUJER: Tres somos, dos quedamos, uno volverá. En la mañana tibia soñé contigo [...]. En la arena tus pies descalzos no dejaban huella y el pez con sus aletas diminutas hizo un pequeño caminito al mar en que caíste [...]. Nuestros antepasados vivieron felices escuchando el ruido del mar y el silencio de la tierra. Así por todos los tiempos. Y eran dueños de su tierra. El mundo estaba bajo sus pies [...]. Las familias han de estar juntas. Así ha sido desde todos los tiempos. La tierra necesita tus brazos, y este año ha llovido mucho [...]. Esta es tu casa, recuérdalo bien. Serás afortunado si el sabio Dios te encuentra en sus dominios cuando venga por nosotros; de lo contrario otros dioses se encargarán de tu abandono (Vallejo 2004: 39-41).

De manera inconfundible el autor despliega un discurso apologético a las raíces cuyos «dueños» eran nuestros antepasados y el infortunio que supone el abandono y el olvido de la tradición o su sustitución por una cultura nueva. La dicotomía entre el movimiento y el arraigo presenta el elemento inherente al conflicto dramático íntimo de los protagonistas, Por un lado, el desplazamiento incita como la palabra «ultramarinos» a Juan, el personaje hispanoamericano, «como el mar...ultra, extremo, adentro, lejano, otros mares, otras gentes, otras lenguas, sabores, olores, personas, mundos» (Vallejo 2004: 31), donde la imagen del viaje marítimo suscita «la posibilidad de un desarrollo literario y teatral, en cuanto que entronca con rasgos que caracterizan al viaje clásico a una tierra prometida. El viaje se sitúa así en los confines entre la aventura, la huida y la conquista de un nuevo territorio» (Pérez-Rasilla 2010: 99). Sin embargo, el viaje también supone peligro que amenaza la pérdida de la identidad en el mar que «se lo come todo», en cuyo fondo «la sangre no se ve tan roja» (Vallejo 2004: 46) y donde no cabe el peso de la memoria.

Al mismo tiempo, en el caso del (e/in)migrante el olvido es imprescindible para poder superar el trauma de la separación, de la historia rota, y sobrevivir dentro del código cultural nuevo:

JUAN: Lo único que sé es que allí se olvidan las cosas muy fácilmente. No puedes recordarlo todo. Si te acuerdas, sufres. Tienes que pensar en el día a día para sobrevivir (Vallejo 2004: 36).

OBO: Salí corriendo, salvé dos libros, los zapatos, no podía regresar. Camino desde el centro el mundo sin saber adónde ir. Quise regresar, ya estaba muy lejos. Di todo mi dinero para que me trajeran, luego vino el mar, noche de miedo y gritos. No sabía que fuera un camino tan largo.

JUAN: ¿Y los libros?

OBO: En alguna duna del desierto.

JUAN. Alguien los leerá...

ONO: Eso espero, pesaban demasiado.

MUSTAPHA: Pero has encontrado tu zapato.

OBO: Ahora puedo continuar mi viaje (Vallejo 2004: 44). 
El leitmotiv del zapato perdido (o encontrado), el mar y la arena de la playa o del desierto se reiteran como los símbolos del viaje, mientras los libros, la ropa y los objetos esparcidos en la orilla que recibe a los (in)migrantes y que sus familiares posteriormente buscan, encuentran y «aferrra[n] a su pecho» (Vallejo 2004: 54) obviamente representan los restos de la memoria, abandonada en la tierra nueva o perdida durante el naufragio. El autor materializa la idea del recuerdo en el objeto que se puede perder, buscar, encontrar, heredar o incluso negociar como muestra la oferta que hace el Sepulturero a la madre de uno de los (e)migrantes: «SEPULTURERO: Mire, dejémoslo a mitad de precio y el próximo jueves podrán rezar tranquilamente con su presencia. Es mi última oferta. Lo digo por su tranquilidad, señora. Cincuenta por ciento, las flores y la foto del sitio donde descansa el primero» (Vallejo 2004: 39). Refiriéndonos una vez más a los estudios antropológicos sobre la migración, el texto dramático encierra uno de los conceptos dominantes sobre la simbología del viaje donde «un objeto (o un evento, un acto, una emoción) se define mediante la colocación en el contexto de un símbolo apropiado») ${ }^{12}$ (Geertz 1973: 215) que sirve de guía en la conexión de los lugares y las rutas no pertenecientes a los mapas y fronteras oficiales, sino a una geografía personal del individuo postmoderno.

Un sistema simbólico parecido se encuentra en la construcción dramática que sostienen los cuatro monólogos de Botto y Cossa, donde cada texto ofrece un enfoque distinto sobre el tema (in)migrante: El privilegio de ser perro, que da el título a la obra, proporciona la visión del inmigrante en situación precaria sin conseguir integrarse en la sociedad de acogida; Arquímedes contrasta esta perspectiva otorgándole la voz al funcionario español en una oficina de inmigración; La carta cuenta un hecho real, el destino trágico de dos niños africanos fallecidos en el tren de aterrizaje de un avión mientras intentaban entrar clandestinamente a España; y finalmente, Definitivamente, adiós dramatiza la historia reiterada de exilio de varias generaciones familiares cuyas vidas transcurrieron entre España y Argentina. El escenario que vincula todas las partes de la obra

... está constituido por una montaña de maletas, creando un espacio abstracto que puede sugerir una terminal de aeropuerto, una terminal de trenes o una gigantesca nave donde los nazis acumulaban las pertenencias de los desposeídos que eran conducidos a los campos de concentración. Dentro de algunas de estas maletas hay arena. Durante los monólogos primero y segundo la acción del actor consistirá en abrir las maletas y desparramar su contenido (Botto y Cossa 2005: 9).

\footnotetext{
$12 \ll \ldots$ an object (or an event, an act, an emotion) is defined by placing it against the background of an appropriate symbol».
} 
Como en el ejemplo anterior, el bagaje cultural, el peso del recuerdo y los restos de la memoria se materializan en los objetos visibles: las maletas acumuladas que ocupan el escenario y la arena como la evocación de la tierra natal. Al abandonar los orígenes, la memoria invade el espacio mental por completo, destruida y transformada en los desperdicios del pasado y la arena convertida en la nada.

Entre los cuatro textos, El privilegio de ser perro y Definitivamente, adiós resultan los más interesantes para este estudio, dado que ofrecen la visión de inmigrantes adultos cuyos discursos se inscriben en el concepto de historia rota. El primero problematiza el desplazamiento y la semiótica (e/in)migrante que construye los parámetros de su identidad:

Pienso en un pasaje, un aeropuerto, un avión, una gran vomitona en el baño del 747 , ver el océano que te separa cada vez más de tu casa y te lleva vete a saber dónde. Y después otro aeropuerto, una habitación de hotel y ¡tachán! Ya eres un inmigrante. Se tardan trece horas en cambiar de status de emigrante a inmigrante. De ser parte de... a no ser parte de nada. ¡Pam!, ahora tengo un marco que me contiene, estoy rodeado de gente que conozco, de calles que me conocen, de recuerdos en un quiosco, en un bar, en un colegio, y de repente estoy rodeado de gente que no sabe nada de mí, calles que no saben nada de mí y en general de todo un mundo al que le importo una mierda (Botto y Cossa 2005: 16-17).

El autor dramatiza el paradigma de la migración dentro del contexto postnacional y postmoderno de los «no-lugares» (Augé 1992) que se manifiesta como un movimiento continuo del individuo que no llega a crear los espacios simbólicos constantes. En la era postnacional el sujeto se aferra a las identidades temporales desprovistas de memoria y referencialidad concreta, activando varios códigos culturales en los múltiples contextos que requiere un determinado no-lugar. Por estas razones los personajes asumen una identidad inestable y están siempre fuera del sitio y del tiempo definido por las coordenadas de la memoria. A partir del primer desplazamiento la ruptura se convierte en un hecho constante que va a marcar su vida para siempre porque el retorno espacio-temporal a las raíces es imposible, dado que «la gente ya no te conoce, las calles ya no te conocen, ese quiosco, ese bar, ese colegio que guardaban secretos de tu juventud parecen cambiados y parece que esos lugares y esa historia que recordabas ya sólo existe en tu cabeza, como sombras de un pasado sin testigos» (Botto y Cossa 2005: 23). Como en otros textos presentados, el pasado se personifica como el testigo que olvida y abandona a sus expatriados.

El último monólogo, Definitivamente, adiós trata explícitamente el concepto de la memoria y la postmemoria; los personajes heredan nombres, recuerdos, actitudes políticas y destinos que perpetúan los conceptos de diáspora como la desvinculación respecto a la tierra natal y la perduración de las convicciones políticas en la postmemoria. El mismo actor se desdobla en varios personajes, encarnando la imagen del abuelo en el recuerdo del hijo, del nieto y del bis- 
nieto, todos unidos por el canturreo de la canción de la Guerra Civil que se hereda y perdura mucho después de que el conflicto se acabara y los verdaderos participantes fallecieran. La melodía forma parte del repertorio familiar como el elemento constructivo de la memoria en una «museología nueva» (Hirsch 2008: 105) que pertenece a los archivos íntimos de la persona y se transmite dentro de la institución de la familia con un resultado mucho más involucrado en la construcción de la identidad que la historia nacional.

Finalmente, a estas propuestas dramáticas se suma el drama La mirada del hombre oscuro, de Ignacio del Moral, cuyo protagonista también llega a la costa española sin conseguir abandonar su pasado y la miseria en que se encuentra sometido. Esta obra principalmente enfoca la violencia y el rechazo por parte de la sociedad de acogida, personificada en una familia española que se cruza con el personaje principal, Ombasi, en la misma orilla, donde el contacto con el Otro descubre sus propios miedos, histerias y la imposibilidad de comunicación y comprensión humana. Sin embargo, la historia rota del personaje (in)migrante es el motivo inherente de la obra y el núcleo que define al protagonista. El viaje en patera otra vez simboliza el primer paso del desarraigo:

Entre sonido de músicas tribales Africanas, oímos voces y sonidos que reconstruyen la odisea de Ombasi y su amigo. Voces en varios idiomas. Se mezclan español, francés y árabe.

Quince mil por llegar a Tarifa [...]. Venga, negro, sube o te quedas aquí [...]

Ruido de mar, olas, viento, truenos.

¡Sois demasiados!, tirad todo lo que llevéis.

El ruido del agua aumenta, chapoteos, jadeos, la respiración agitada de quién está haciendo un esfuerzo superior a sus fuerzas. Ombasi jadea. Se despierta sobresaltado, con el espanto en los ojos (Moral 1992: 24).

Los recuerdos, el motivo de la pérdida de los objetos personales y los ecos de la patria representan un llamamiento de sus raíces, una incursión del pasado en el presente del escape migratorio como una lucha constante entre las raíces y los raíles. La tensión dramática ejercida sobre el papel del protagonista une dos puntos opuestos: la tierra natal, la raíz, personificada en la voz de su amigo fallecido durante el mismo viaje, y el exilio, los raíles, invocados por las promesas de un futuro mejor. Se reiteran los elementos destacados en otras obras analizadas: el peligro del desarraigo dramatizado con el viaje en la patera, y los zapatos como recuerdo de la patria y seña de identidad que impide el exilio [«OMBASI: Mi amigo se ahogó. No se quitó los zapatos.» (Moral 1992: 47)]. Del mismo modo que en los ejemplos anteriores, al romper la historia lineal de su «comunidad imaginada» el protagonista se ve perseguido por la maldición de la migración que le imposibilita alcanzar el cambio deseado. Como bien observa Pérez-Rasilla (2010: 114), tanto Moral como López Mozo, hacen «regresar al inmigrante a su África natal —en el relato de los hechos, 
no en la acción dramática propiamente dicha, puesto que nunca vemos África en el escenario-,$[\ldots]$ en lo que constituye una imagen de ese infierno del que nunca podrá salir o al que se ve abocado a regresar continuamente». El verdadero trauma de la historia rota no lo provoca únicamente la ruptura del relato personal, familiar o nacional, sino la imposibilidad de separar completamente los períodos, territorios y circunstancias vitales entre el pasado y el futuro del (in)migrante. Dado que la grieta en su historia nunca se parte del todo, la rotura permanece visible y dolorosa como una herida sin cicatrizar que mantiene una tensión permanente entre las raíces y los raíles.

\section{CONCLUSIÓN: El DESAJUSTE ENTRE EL TEXTO Y LA REPRESENTACIÓN}

Aunque el tema de la inmigración a veces no ha sido debidamente tratado en la dramaturgia española (Kunz 2002), hay que reconocer que los dramaturgos abrieron un ciclo temático nuevo con enfoques muy variados y críticos respecto a la sociedad de acogida ${ }^{13}$. La mayoría de ellos intentó dar una mayor visibilidad al extranjero en la vida pública y apostaron por los proyectos teatrales internacionales y polifónicos que permitieron incorporar distintos acercamientos a los problemas en cuestión. Sin embargo, a pesar de la actualidad del tema, pocos textos se han llevado a la escena y tampoco se representaron en condiciones equivalentes a la calidad del texto escrito. De los dramas comentados en este trabajo llegaron a estrenarse solamente La mirada del hombre oscuro (1993, dirección: Ernesto Caballero; 1997, dirección: Federico Monserrat), Los viernes del Hotel Luna Caribe (2000, dirección: Fermín Cabal), Patera (2004, dirección: Pitus Fernández) y los cuatro monólogos reunidos bajo el título El privilegio de ser perro (2005, dirección: Juan Diego Botto). Salvo la obra de Moral, otras no han vuelto a representarse desde entonces, mientras el texto Alhán se dio a conocer a través de lectura dramatizada en $1992^{14}$. Además de los textos estudiados, un gran número de obras (varias de ellas también premiadas) del mismo ciclo temático no llegó a difundirse desde el escenario y su receptor solo pudo haber sido el lector culto, interesado por el

13 Como indicamos anteriormente, la bibliografía dramática sobre el tema (in)migrante en el período estudiado es extensa: David Planell (1996): Bazar, Ignacio del Moral (1997): Boniface y el rey de Ruanda, José Luis Alonso de Santos (1998): Salvajes, Yolanda Pallín (1999): Lista negra, Mahor Galilea Pascual (1999): ¡Comed mucha fruta!, Sara Rosenberg (1999): Emigrantes, Carles Batlle (2000): Combate (Paisaje para después de la batalla), Paloma Pedrero (2001): Cachorros de negro mirar, Jesús Laiz (2002): Phil o Sophía, José Cruz (2003): Taihú, cabaret oriental, Juan Mayorga (2003): Animales nocturnos, Francisco José Martínez Cernadas (2003): Amarga ilusión, Ignacio Amestoy (2006): De Jerusalen a Jericó, Sergi Belbel (2006): Forasteros, y Fermín Cabal (2007): Maldita cocina.

${ }_{14}$ Según los datos recogidos por el Centro de Documentación Teatral. http://teatro.es/ estrenos-teatro (Consulta: 12/01/2016). 
teatro o por la materia en cuestión, ya que la escritura dramática no goza de una popularidad masiva entre los lectores.

El espectáculo es el medio por el cual se consigue masificar la recepción del teatro escrito y donde se muestra con especial intensidad su faceta social, pero en estos casos no alcanzó el nivel de la escritura, puesto que todavía no pudo contar con la participación de los profesionales extranjeros cuyas voces intentó hacer sonar desde la escena. Según Iglesias Santos (2010: 12), los inmigrantes en España carecían de voz propia, dado que en la entrada del siglo XXI todavía no habían nacido las segundas generaciones para poder tomar «ese lugar de enunciación y relata[r] desde su propio yo su experiencia de transculturación, sus problemas de identidad». Aunque aceptemos que el lenguaje teatral tiene que apropiarse de una estética particular que cuente con un espectador colaborativo y el aparato escénico-ilusionista, los ajustes escénicos en cuanto a la edad, la raza o el idioma de los protagonistas no eran de índole estética, sino impuestos por la carencia de los profesionales que pudieran asumir los papeles del extranjero y participar en un auténtico diálogo inherente al género teatral. En su estudio sobre los retos del arte dramático en la era posmoderna, Lehmann (2013: 431) señala que este fenómeno se debe a la inexistencia de una comunicación intercultural verdadera entre distintos códigos culturales y lenguajes escénicos, a pesar de varios experimentos realizados en ese campo a partir de la segunda mitad del siglo XX: «Una ambigüedad subyacente continuará existiendo en la comunicación intercultural mientras las formas de expresión cultural sean también formas de la cultura del poder político dominante o de la cultura oprimida, entre las cuales no puede existir comunicación».

En cuanto a las obras analizadas, las puestas en escena buscaron un lenguaje simbólico transnacional sin especificaciones locales de las minorías extranjeras, evidentemente tratando de reconciliar los códigos culturales en el teatro creado por y para el público español. Sin embargo, el teatro posmoderno y posdramático tampoco tiende a lograr la autenticidad de la vida real en el mimetismo escénico. El hecho teatral de la posmodernidad debería asumir la voz discrepante y afrontar «cada vez más decididamente la propia cultura con un cierto extrañamiento, y tom[ar] una posición disidente, divergente y marginal dentro de la misma» (Lehmann 2013: 432). El espectáculo, como arte de ilusión, debería romper la misma y cuestionar su propio código representativo mediante el alejamiento y la quiebra del marco ilusionista que pueden involucrar a todos los participantes - actores y espectadores - a la hora de cuestionar los signos culturales y crear sus nuevos significados en la escena.

El teatro es capaz de reaccionar a ello solo con una politica de percepción que, al mismo tiempo, podría llamarse una estética de la responsabilidad (o de la capacidad de respuesta). En lugar de la dualidad engañosa y tranquilizadora de aquí y allí, dentro y fuera, puede trasladar la inquietante implicación mutua de 
actores y espectadores en la producción teatral de la imagen como elemento central y así dejar visible el hilo roto que existe entre percepción y experiencia propia (Lehmann 2013: 447).

De esta premisa se deduce que el teatro posmoderno y, en este caso, de tema multicultural tiene al mismo tiempo una obligación ética y estética con la sociedad. Aunque sus recursos todavía carecen de todos los medios para tratar la cuestión (in)migrante desde un enfoque comunicativo y una verdadera mediación intercultural, el aparato teatral como sistema de signos de los signos (los signos escénicos que representan los signos culturales) tiene la capacidad de doblar/cuestionar/subvertir los significados culturales y así proporcionar una visión invertida y crítica sobre lo otro y lo propio, que puede ofrecer los paradigmas nuevos de su interpretación en el contexto transcultural.

\section{BIBLIOGRAFÍA CITADA}

Anderson, Benedict (1990). Nacija: zamišljena zajednica. Razmatranja o porijeklu i širenju nacionalizma. Zagreb: Školska knjiga.

Arija Martínez, Malco (2003). Akua, perdida en el tiempo. Teatro, Promoción RESAD, 1998-2002. Madrid: Espiral/Fundamentos.

Augé, Marc (1992). Non-lieux, introduction à une anthropologie de la surmodernité. Seuil: La Librairie du $\mathrm{XX}^{\mathrm{e}}$ siècle.

Augé, Marc (1998). Las formas de olvido. Barcelona Editorial: Gedisa.

Batlle, Carles (2005). Tentación. Madrid: Sociedad General de Autores y Editores.

Bhabha, Homi (2006). The Location of Culture. London-New York: Routledge Classics.

Botto, Juan Diego y Roberto Cossa (2005). El privilegio de ser perro. Barcelona: El Aleph Editores.

Casso Basterrechea, Alberto de (2000). «Los viernes del Hotel Luna Caribe», Primer Acto. 283, II/2000, pp. 65-113.

Clifford, James (1997). Routes - Travel and Translation in the Late Twentieth Century. Cambridge, London: Harvard University Press.

Conte Imbert, David (2010). «Espacios discursivos de la inmigración», en Montserrat Iglesias Santos (ed.), Imágenes del Otro. La identidad e inmigración en la literatura y el cine. Madrid: Editorial Biblioteca Nueva, pp. 33-56.

Eagleton, Terry (2002). Ideja kulture. Zagreb: Jesenski i Turk.

Enzensberger, Hans Magnus (2002). La gran migración. Treinta y tres acotaciones. Barcelona: Anagrama.

Foguet i Boreu, Francesc (2005). «Parábola de la identidad», en Carles Batlle, Tentación. Madrid: Sociedad General de Autores y Editores, pp. 13-20.

Geertz, Clifford (1973). The Interpretation of Cultures. New York: Basic Books.

Hirsch, Marianne (2008). «The Generation of Postmemory», Poetics Today. 29 (1), pp. 103127.

Hobsbawm, Eric (2002). «Introduction: Inventing Traditions», en Eric Hobsbawm y Terence Ranger (eds.), The Invention of Tradition. Cambridge: Cambridge University Press, pp. 1-14. 
Iglesias Santos, Montserrat (2010). «Representar al otro: Los imaginarios de la inmigración», en Montserrat Iglesias Santos (ed.), Imágenes del Otro. La identidad e inmigración en la literatura y el cine. Madrid: Editorial Biblioteca Nueva, S.L., pp. 9-19.

Kunz, Marco (2002). «El drama de la inmigración: La mirada del hombre oscuro de Ignacio del Moral y Ahlán de Jerónimo López Mozo», en Irene Andres-Suárez, Marco Kunz e Inés D’Ors (eds.), La inmigración en la literatura española contemporánea. Madrid: Verbum, pp. 215-256.

Lehmann, Hans-Thies (2013). Teatro posdramático. Murcia: Cendeac.

López Mozo, Jerónimo (1997). Ahlán. Madrid: Agencia Española de Cooperación Internacional.

Lukács, György (1962). The Historical Novel. England: Penguin Books.

Monleón, José y Nel Diago (2007). «Teatro, memoria e historia», en José Monleón y Nel Diago (eds.), Teatro, memoria e historia. Valencia: Universidad de Valencia, pp. 9-11.

Moral, Ignacio del (1992). La mirada del hombre oscuro. Madrid: Fundación Autor.

Pérez-Rasilla, Eduardo (2010). «Representación de la inmigración en el teatro español contemporáneo», en Montserrat Iglesias Santos (ed.), Imágenes del Otro. La identidad e inmigración en la literatura y el cine. Madrid: Editorial Biblioteca Nueva, pp. 87-115.

Ricœur, Paul (1999). Historia y narratividad. Barcelona: Ediciones Paidós, Universidad Autónoma de Barcelona.

Vallejo, Juan Pablo (2004). «Patera», Primer Acto. 302, I, pp. 26-54.

White, Hayden (1987). The Content of the Form- Narrative discourse and Historical Representation. Baltimore and London: The Johns Hopkins University Press.

Fecha de recepción: 17 de marzo de 2016.

Fecha de aceptación: 25 de noviembre de 2016. 